SOI: $1.1 /$ TAS $\quad$ DOI: $10.15863 /$ TAS

\section{International Scientific Journal Theoretical \& Applied Science}

\author{
p-ISSN: 2308-4944 (print) e-ISSN: 2409-0085 (online) \\ Year: $2018 \quad$ Issue: 03 Volume: 59
}

Published: $13.03 .2018 \quad$ http://T-Science.org
Elena Anatolievna Chalenko candidate of technical Sciences, Associate Professor Department of Artistic modelling, design and technology of garments

The Kosygin State University of Russia (Kosygin University ) ele-ela@yandex.ru

SECTION 25. Technologies of materials for the light and textile industry.

\title{
DEVELOPMENT OF CLASSIFICATION OF FEATURES OF SPORTS CLOTHES FOR LESSONS WITH BALL DANCES AND FIGURE SKATING
}

Abstract: For the first time, a classification of different types of clothing designed for sports ballroom dancing and figure skating on a professional level has been developed. This study is aimed at further automation of works on the selection of structural solutions and methods of making garments for sports.

Key words: sportswear, figure skating, ballroom dancing, classification, highly elastic materials, finishing materials, shoulder products, belt products, combined products, training suit, costume for performances.

Language: Russian

Citation: Chalenko EA (2018) DEVELOPMENT OF CLASSIFICATION OF FEATURES OF SPORTS CLOTHES FOR LESSONS WITH BALL DANCES AND FIGURE SKATING. ISJ Theoretical \& Applied Science, 03 (59): 54-61.

Soi: http://s-o-i.org/1.1/TAS-03-59-9 Doi: crossef https://dx.doi.org/10.15863/TAS.2018.03.59.9

\section{РАЗРАБОТКА КЛАССИФИКАЦИИ ОСОБЕННОСТЕЙ СПОРТИВНОЙ ОДЕЖДЫ ДЛЯ ЗАНЯТИЙ БАЛЬНЫМИ ТАНЦАМИ И ФИГУРНЫМ КАТАНИЕМ}

Аннотация: Впервые разработана классификация различных видов одежды, предназначенных для занятий спортивными бальными танцами и фигурным катанием на коньках на профессиональном уровне. Данное исследование направлено на дальнейшую автоматизацию работ по подбору конструктивных решений и методов изготовления швейных изделий для занятий спортом.

Ключевые слова: спортивная одежда, фигурное катание, бальные танцы, классификация, высокоэластичные материалы, отделочные материалы, плечевые изделия, поясные изделия, комбинированные изделия, костюм для тренировок, костюм для выступлений.

Введение. Возросший в последнее время в обществе интерес к здоровому образу жизни и спорту вызывает насущную необходимость в изготовлении широкого ассортимента качественной одежды для занятий данным видом деятельности [1]. Выпускаемый промышленностью в настоящее время ассортимент спортивной одежды можно разделить на одежду для занятий физической культурой и одежду для занятий спортом на профессиональном уровне.

Объекты и методы исследования. Одежду для занятий физической культурой можно условно отнести к бытовой, имеющей достаточно широкое распространение. Данным изделиям, как и всем видам бытовой одежды дизайнеры уделяют достаточно много внимания, разрабатывая новые модели, совершенствуя методы конструирования и моделирования, применяя современные высокотехнологичные материалы, совершенствуя методы изготовления.

В то же время большой интерес представляет разработка одежды для занятий спортом на уровне высшего профессионального мастерства [2-10]. Большой интерес для исследований представляет разработка одежды для занятий высококоординационными видами спорта, такими как фигурное катание, спортивная и художественная гимнастика, спортивные бальные танцы и другие. Внешний вид, конструктивные и цветовое решения, отделка таких костюмов регламентируются, так как они должны подчеркивать принадлежности спортсмена к определенному виду спорта и команде. В каждом виде спорта есть свои 


\begin{tabular}{|c|c|c|c|c|c|c|}
\hline Impact Factor: & $\begin{array}{l}\text { ISRA (India) } \\
\text { ISI (Dubai, UAE } \\
\text { GIF (Australia) } \\
\text { JIF }\end{array}$ & $\begin{array}{r}=1.344 \\
=0.829 \\
=0.564 \\
=1.500\end{array}$ & $\begin{array}{l}\text { SIS (USA) } \\
\text { PИНЦ (Russia) } \\
\text { ESJI (KZ) } \\
\text { SJIF (Morocco) }\end{array}$ & $\begin{array}{l}=0.912 \\
=0.207 \\
=4.102 \\
=2.031\end{array}$ & $\begin{array}{l}\text { ICV (Poland) } \\
\text { PIF (India) } \\
\text { IBI (India) }\end{array}$ & $\begin{array}{l}=6.630 \\
=1.940 \\
=4.260\end{array}$ \\
\hline
\end{tabular}

особенности выполнения упражнений, условий в которых они выполняются, особенностей физического развития спортсменов. Эти и многие другие факторы в совокупности влияют на внешний вид костюма спортсмена.

В работе подробно рассмотрены костюмы для спортивных бальных танцев и фигурного катания на коньках, так как эти виды спорта имеют общие черты двигательной деятельности и схожесть конструктивных решений костюмов для выполнения упражнений.

Результаты и обсуждение. С целью ознакомления с современным ассортиментом спортивной одежды для занятий фигурным катанием (ФК) и бальными танцами (БТ), разработан классификатор (рис. 1). В основе которого лежат потребительские признаки, к которым относятся:

1. Основной признак, характеризующий половозрастную и размерную принадлежность изделия, а также его целевое назначение;

2. Вид изделия, где перечень изделий разделен на группы плечевых, поясных, комбинированных и чулочно-носочных изделий;

3. Материалы, применяемые для изготов-ления спортивной одежды, выбранных видов спорта.

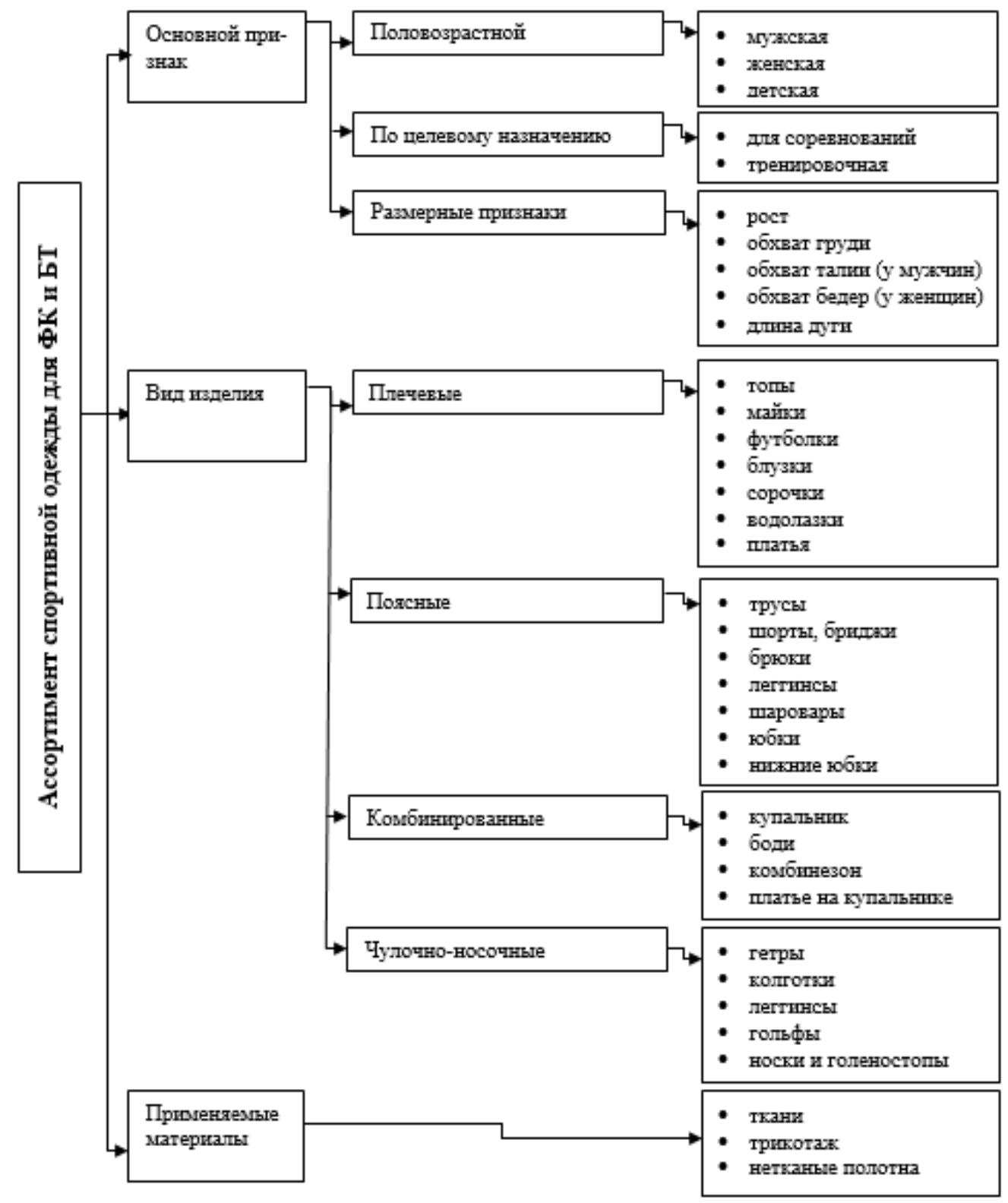

Рисунок 1 - Классификатор общих признаков, характеризующих спортивную одежду для фигурного катания и бальных танцев. 


\begin{tabular}{l|lr|ll|ll} 
& ISRA (India) & $=\mathbf{1 . 3 4 4}$ & SIS (USA) & $=\mathbf{0 . 9 1 2}$ & ICV (Poland) & $=\mathbf{6 . 6 3 0}$ \\
Impact Factor: & ISI (Dubai, UAE) $=\mathbf{0 . 8 2 9}$ & PUHЦ (Russia) $=\mathbf{0 . 2 0 7}$ & PIF (India) & $=\mathbf{1 . 9 4 0}$ \\
& GIF (Australia) & $\mathbf{0 . 5 6 4}$ & ESJI (KZ) & $=4.102$ & IBI (India) & $=\mathbf{4 . 2 6 0}$ \\
& JIF & $=\mathbf{1 . 5 0 0}$ & SJIF (Morocco) & $=\mathbf{2 . 0 3 1}$ & & \\
\hline
\end{tabular}

Ассортимент спортивной одежды для фигурного катания на коньках и спортивных бальных танцев многообразен, и большей своей частью изготавливается из трикотажных материалов разной степени эластичности [4, 915]. При этом одежда для тренировок полностью включает в себя весь ассортимент всевозможных изделий, в то время как в изделиях для соревнований преобладает комбинированная группа изделий.

В качестве объекта исследования выбрана женская спортивная одежда из эластичных и высокоэластичных материалов [5, 9, 11, 12, 1419]. В работе разработана классификационная система, созданная в результате деления и группирования объекта исследования на разновидности по различным признакам.

При детальном рассмотрении представленных видов одежды, были разработаны классификаторы особенностей большинства видов спортивной одежды. Для примера рассмотрим классификатор спортивных изделий плечевой группы (рис. 2) деление осуществлялось по следующим признакам:

$\square$ Конструктивно-технологические характеристики изделий;

$\square$ Особенности, присущие спортивной одежде плечевой группы;

$\neg$ Информация о применяемых материалах.

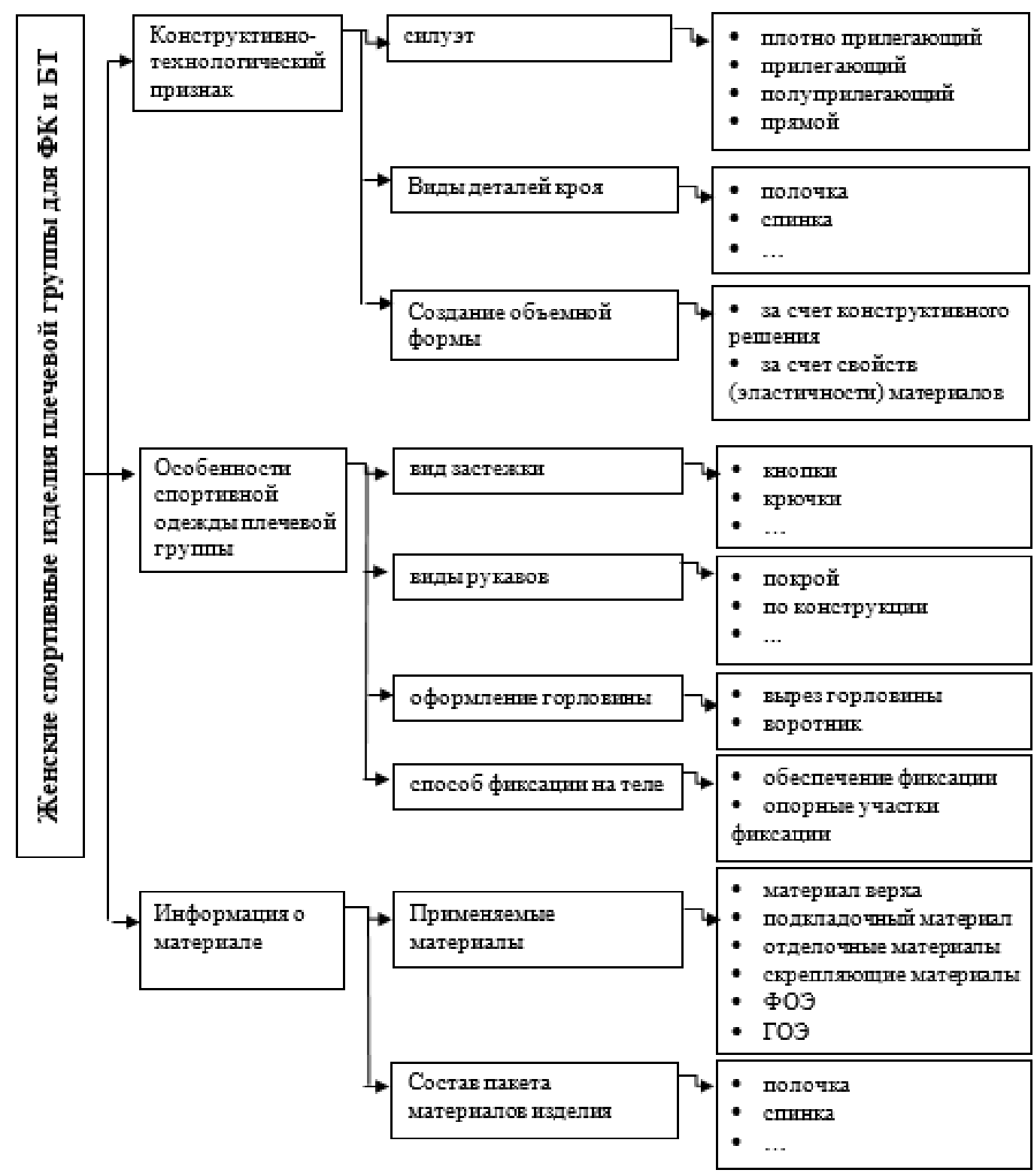

Рисунок 2 - Классификация общих признаков, характеризующих спортивную одежду плечевой группы для фигурного катания и бальных танцев. 


\begin{tabular}{|c|c|c|c|c|c|c|}
\hline Impact Factor: & $\begin{array}{l}\text { ISRA (India) } \\
\text { ISI (Dubai, UAE } \\
\text { GIF (Australia) } \\
\text { JIF }\end{array}$ & $\begin{array}{r}=1.344 \\
=0.829 \\
=0.564 \\
=1.500\end{array}$ & $\begin{array}{l}\text { SIS (USA) } \\
\text { PИНЦ (Russia) } \\
\text { ESJI (KZ) } \\
\text { SJIF (Morocco) }\end{array}$ & $\begin{array}{l}=0.912 \\
=0.207 \\
=4.102 \\
=\mathbf{2 . 0 3 1}\end{array}$ & $\begin{array}{l}\text { ICV (Poland) } \\
\text { PIF (India) } \\
\text { IBI (India) }\end{array}$ & $\begin{array}{l}=6.630 \\
=1.940 \\
=4.260\end{array}$ \\
\hline
\end{tabular}

По каждому из признаков выделены основные характеристики.
1. По признаку
конструктивно-
технологической характеристики:
$\square$ силуэт
виды деталей кроя;
способ создания объемной формы.

2. По признаку «особенности спортивной одежды плечевой группы»:

$\square$ вид застежки;

$\square$ покрой рукава;

$\square$ оформление горловины;

$\square$ способ фиксации на теле.

3. По признаку информации о применяемых материалах:

$\square$ виды применяемых материалов;

$\square$ состав пакета материалов изделия.

Целью разработки классификаций является получение общего представления о художественных, конструктивно-технологических особенностях тренировочной одежды и одежды для соревнований по спортивным бальным танцам и фигурному катанию, получение информации о возможных составах пакетов изделий [19], выявление участков, сложенных в обработке, а также участков, подверженных деформациям вызывающим дефекты внешнего вида для дальнейшей автоматизации работ по формированию конструктивных и технологических решений данных изделий $[20,21]$.

По конструктивно-технологическому признаку изделия плечевой группы преимущественно имеют прилегающий и плотно прилегающий силуэт, но также встречаются и изделия прямого силуэта.

В изделиях плечевой группы применяются следующие детали кроя: полочка, перед платья, спинка, рукава, воротник, бретели. В различных моделях некоторые детали кроя могут отсутствовать. Например, может отсутствовать спинка при наличии бретелей и перемычки из эластичной тесьмы, фиксирующей полочки или перед. Рукава, воротник и бретели могут быть цельнокроеными с деталями стана. Все детали кроя могут состоять как из одной, так и из нескольких частей. Части изделия могут быть выполнены из разных материалов, последовательно соединенных, и иметь разное количество слоев.

По признаку особенности спортивной одежды плечевой группы выделены следующие характеристики: вид застежки, вид рукава, оформление горловины и способ фиксации на теле спортсмена.

Виды застежки в спортивной одежде для тренировок и соревнований разнообразны. Застежка в спортивной одежде может быть бортовой, располагаться в плечевом, боковом, рельефном, среднем срезе спинки, шаговом срезе брюк или отсутствовать. Застегивание изделий может осуществляться на кнопки, крючки и петли, на спецзастежки, на тесьму «молнию», на пуговицы и навесные или обметанные петли. На отдельных участках застегивание может производиться на текстильную тесьму велькро («липучку».)

По признаку информация о материале классифицированы применяемые материалы [12, $13,22-24]$ и составы пакетов $[15,16,19]$ изделий плечевой и группы (рис. 3).

Для изготовления тренировочной и соревновательной одежды по спортивным бальным танцам и фигурному катанию применяются трикотажные и нетканые полотна. В качестве материала верха и подкладки могут выступать одни и те же материалы. Трикотажные полотна по виду переплетения - гладь, ластик, двуластик, трико, атлас, прессовое, платированное, ажурное, футерованное, и комбинированные - трико-сукно, трико-ластик, трико-сукно ажурное. Волокнистый состав полотен может содержать хлопчатобумажные волокна, вискозу, ацетат, лавсан, капрон, нитрон, эластан, полиамид, полиэстер, лайкру и спандекс. По растяжимость трикотажные материалы различают: растяжимые и высокорастяжимые в одном или двух направлениях. Полотна могут иметь следующие виды отделки - напыление (точечное, узорчатое), голографическую отделку, пайетки; печатный или набивной рисунок, лаке, эффект «мятой» поверхности. Ткани применяются полотняного, атласного, сатинового переплетения. По волокнистому составу - шелк, вискоза, ацетат, лавсан, капрон, эластан. Ткани могут быть гладкокрашеными, с рисунком, с напылением, эффектом плисе и гофре. Применяют растяжимые, высокорастяжимые и нерастяжимые ткани.

Для изготовления и декорирования костюмов для соревнований применяется большое разнообразие готовых отделочных материалов и элементов (ГОЭ). В то же время тренировочные костюмы более сдержаны в декоративном оформлении. В качестве отделочных материалов применяются эластичные и неэластичные тканые, нетканые, плетеные и вышитые полотна, такие как кружева, лейскружево, гипюр, сетка жесткая, сетка мягкая, вуаль, твинкл. По виду отделки они могут быть гладкими, металлизированными, расшитыми бисером, камнями или пайетками, расклеенными стразами, с объемными элементами.

Также применяется широкий спектр функционально-отделочных элементов (ФОЭ), куда входит огромное количество лент, кружев и тесем, бахрома, ригилин, всевозможные бейки. 


\begin{tabular}{l|lr|ll|ll} 
& ISRA (India) & $=\mathbf{1 . 3 4 4}$ & SIS (USA) & $=\mathbf{0 . 9 1 2}$ & ICV (Poland) & $=\mathbf{6 . 6 3 0}$ \\
Impact Factor: & ISI (Dubai, UAE) $=\mathbf{0 . 8 2 9}$ & PUHL (Russia) $=\mathbf{0 . 2 0 7}$ & PIF (India) & $=\mathbf{1 . 9 4 0}$ \\
& GIF (Australia) & $=\mathbf{0 . 5 6 4}$ & ESJI (KZ) & $=\mathbf{4 . 1 0 2}$ & IBI (India) & $\mathbf{4 . 2 6 0}$ \\
& JIF & $=1.500$ & SJIF (Morocco) & $=\mathbf{2 . 0 3 1}$ & & \\
\hline
\end{tabular}

Ленты, тесьма и кружево, могут быть изделием клеевым или ниточным способом. эластичными и неэластичными, соединяться с

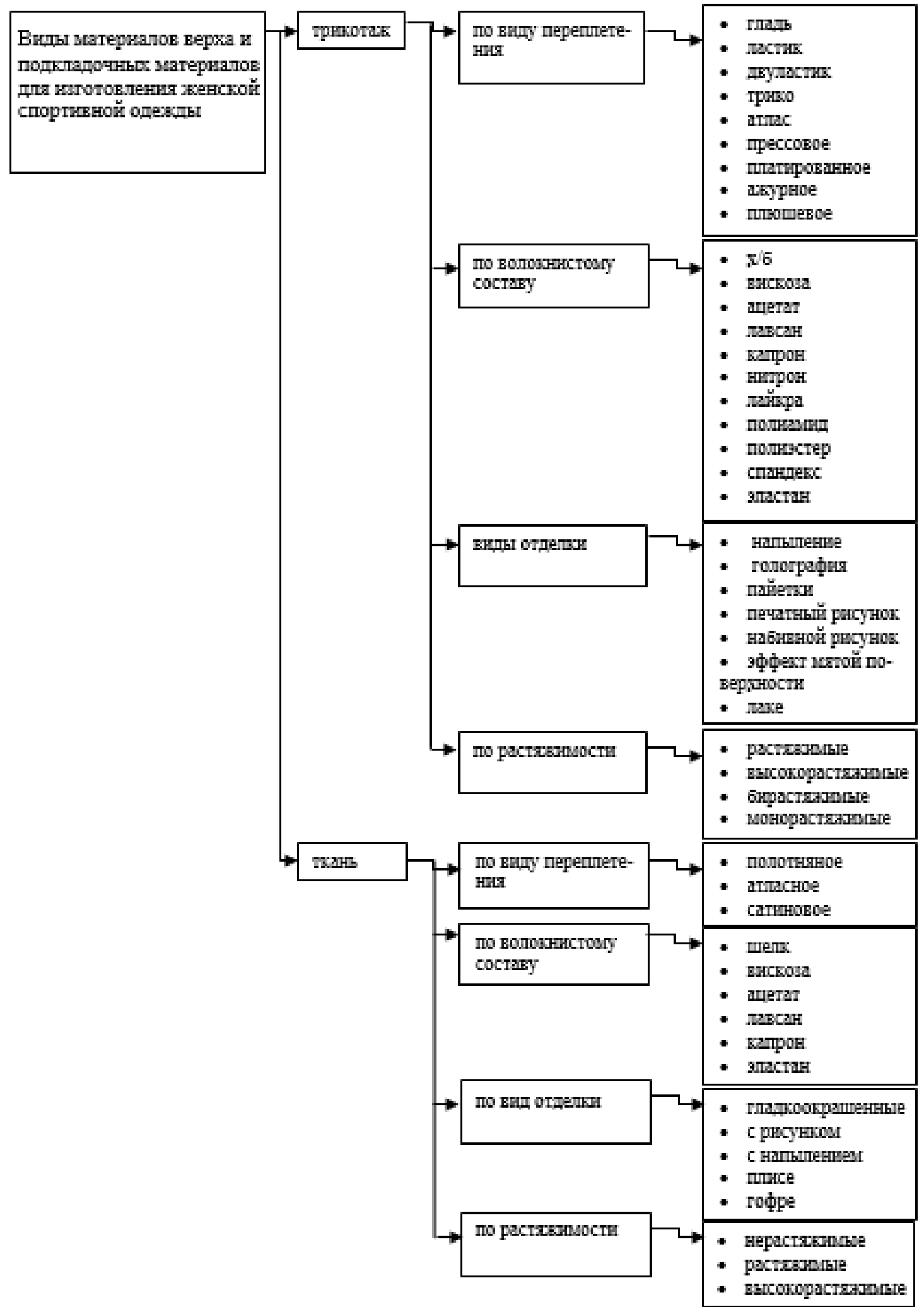

Рисунок 3 - Классификация материалов верха и подкладочных материалов для изготовления женской спортивной одежды. 
Самое большое распространение в отделке спортивной одежды для соревнований получили стразы, бусины и камни. Выпускаются различных размеров, пришивные, клеевые и термоклеевые элементы в виде аппликаций, либо в виде поштучно нанизанных на нить элементов.

Для всех перечисленных элементов спортивных изделий были разработаны классификаторы, позволяющие упростить процесс изготовления спортивных изделий для бальных танцев и фигурного катания еще на стадии проектирования $[25,26]$.

\section{Выводы.}

Таким образом, была разработана классификационная система описывающая конструктивные особенности спортивных изделий плечевой, поясной и комбинированной групп. По каждой из групп рассмотрены основные виды деталей кроя и их части, способы создания объемной формы, способы фиксации изделий на теле спортсмена, основные пакеты изделий на различных участках. Проведенный анализ может стать основой для разработки информационной базы выбора оптимальных методов обработки узлов спортивных изделий с учетом применяемых материалов.

На основе анализа возможных конструктивных решений, применяемых материалов и их сочетаний, анализа видов ниточных соединений, особенностей обработки узлов спортивной одежды для бальных танцев и фигурного катания существенно упрощается процесс разработки конструктивнотехнологических решений типовых моделей тренировочной одежды и одежды для соревнований.

\section{References:}

1. Afanas'yeva A.I., Nefedova L.V., Chalenko E.A., Aksenova I.V. (2015) Organizatsionnotekhnicheskiye usloviya obnovleniya assortimenta v shveynom proizvodstve. Dizayn i tekhnologii. 2015. № 48 (90). p. 22-27.

2. Sanzhiyeva G.V., Chalenko E.A. (2016) Perspektivy razvitiya $\mathrm{V}$ proyektirovanii $\mathrm{i}$ izgotovlenii sportivnoy odezhdy. V sbornike: Sovremennyye tendentsii $\mathrm{v}$ nauke, tekhnike, obrazovanii. Sbornik nauchnykh trudov po materialam Mezhdunarodnoy nauchnoprakticheskoy konferentsii: v 3-kh chastyakh. 2016. p. 101-102.

3. Chalenko E.A., Sanzhiyeva G.V. (2016) Razrabotka metoda proyektirovaniya i izgotovleniya ergonomichnoy sportivnoy odezhdy plotnogo prileganiya. V sbornike: 21 vek: fundamental'naya nauka i tekhnologii Materialy VIII mezhdunarodnoy nauchnoprakticheskoy konferentsii. n.-i. ts. «Akademicheskiy». 2016. p. 123-125.

4. Chalenko E.A., Kirsanova E.A., Vershinina A.V. (2016) Nadezhnost' soyedineniya detaley pri dinamicheskikh nagruzkakh $\mathrm{v}$ sportivnykh izdeliyakh. V sbornike: Modelirovaniye v tekhnike i ekonomike sbornik materialov mezhdunarodnoy nauchno-prakticheskoy konferentsii. Glavnyy redaktor: Vankevich E.V.. 2016. p. 185-187.

5. Safonova N.S., Chalenko E.A., Sanzhiyeva G.V. (2015) K voprosu o proyektirovanii shveynykh obolochek plotnogo prileganiya. V sbornike: Akademicheskaya nauka - problemy i dostizheniya Materialy VII mezhdunarodnoy nauchno-prakticheskoy konferentsii. 2015. p. 221-223.

6. Kirsanova E.A., Chalenko E.A. (2014) Vyyavleniye pervoocherednykh potrebitel'skikh kharakteristik sportivnoy odezhdy metodom strukturirovaniya funktsii kachestva. V sbornike: DIZAYN, TEKHNOLOGII I INNOVATSII V TEKSTIL'NOY I LEGKOY PROMYSHLENNOSTI (INNOVATSII - 2014) sbornik materialov Mezhdunarodnoy nauchnotekhnicheskoy konferentsii. 2014. p. 262-265.

7. Chalenko E.A., Platova A.A., Kupriyanova M.S., Babenkova O.V. (2011) Working out of a swimwear collection on the basis of 1950s fashionable trends. In the collection: Grand Fashion Proceedings. 2011. p. 116.

8. Chalenko E.A., Platova A.A., Murashova N.V., Sanzhieva G.V. (2011) Features of children's gymnastic leotards design of modern materials. In the collection: Grand Fashion Proceedings. 2011. p. 117-118.

9. Chalenko E.A., Kirsanova E.A., Narysheva A.M., Platova A.A. (2009) Kontseptsiya prognozirovaniya svoystv shveynykh izdeliy, ispytyvayushchikh vysokiye dinamicheskiye nagruzki na osnove issledovaniya svoystv materialov. V sbornike: Innovatsii i perspektivy servisa Sbornik nauchnykh statey VI 
Mezhdunarodnoy nauchno-tekhnicheskoy konferentsii. Ufa, 2009. p. 130-132.

10. Kirsanova E.A., Chalenko E.A., Shustov Y.S., Sanzhieva G.V. (2015) Application of quality function deployment method for determining performance properties of sportswear. Fibre Chemistry. 2015. T. 47. № 2. p. 130-132.

11. Demskaya A.A., Kirsanova E.A., Vershinina A.V., Chalenko E.A. (2016) Vliyaniye svoystv materialov i metodov tekhnologicheskoy obrabotki na formirovaniye esteticheskogo vospriyatiya shveynykh izdeliy. Dizayn i tekhnologii. 2016. № 53 (95). p. 51-56.

12. Safonova N.S., Chalenko E.A. (2015) Issledovaniye svoystv materialov dlya tseley proyektirovaniya plotnoprilegayushchikh shveynykh obolochek. V knige: Innovatsionnoye razvitiye legkoy i tekstil'noy promyshlennosti (INTEKS-2015) sbornik materialov Vserossiyskoy nauchnoy studencheskoy konferentsii. Moskovskiy gosudarstvennyy universitet dizayna i tekhnologii. 2015. p. 104-106.

13. Bordacheva A.A., Aksenova I.V., Chalenko E.A., Galayan A.G. (2014) Issledovaniye assortimenta i klassifikatsiya materialov dlya izgotovleniya zhenskikh bel'yevykh izdeliy. Dizayn i tekhnologii. 2014. № 39 (81). p. 3440.

14. Trutneva N.E., Chalenko E.A., Kirsanova E.A., Chizhova N.V. (2014) Uchot svoystv materialov pri dvukhstadiynoy obrabotke shveynykh izdeliy. Dizayn i tekhnologii. 2014. № 43 (85). p. 26-30.

15. Chalenko E.A., Makharashvili G.E., Kirsanova E.A. (2011) Issledovaniye vliyaniya konstruktivnykh i tekhnologicheskikh faktorov na pakety materialov dlya kostyuma. V sbornike: Innovatsii i perspektivy servisa Sbornik nauchnykh statey VII Mezhdunarodnoy nauchno-tekhnicheskoy konferentsii. 2011. p. 187-190.

16. Chalenko E.A. (2017) Vliyaniye tekhnologicheskoy obrabotki na svoystva materialov dlya izgotovleniya shveynykh izdeliy. V sbornike: Rezul'taty sovremennykh nauchnykh issledovaniy i razrabotok sbornik statey pobediteley II Mezhdunarodnoy nauchno-prakticheskoy konferentsii. 2017. p. 61-63.

17. Chalenko E.A. (2017) Teoreticheskiye aspekty preobrazovaniye ploskikh tekstil'nykh materialov $\mathrm{v}$ kompleksy shveynogo izdeliya. Theoretical \& Applied Science. 2017. № 10 (54). p. 203-205.

18. Kirsanova E.A., Chalenko E.A. (2016) Modelirovaniye svoystv materialov legkoy promyshlennosti $\mathrm{v}$ zavisimosti ot formy izdeliy. V sbornike: Aktual'nyye napravleniya fundamental'nykh i prikladnykh issledovaniy Materialy VIII mezhdunarodnoy nauchnoprakticheskoy konferentsii. 2016. p. 62-65.

19. Sanzhiyeva G.V., Chalenko E.A., Ur'yash A.A. (2013) Issledovaniye paketov materialov dlya sportivnykh kupal'nikov. Dizayn i tekhnologii. 2013. № 38 (80). p. 77-83.

20. Chalenko E.A., Aksenova I.V. (2015) Perspektivnyye razrabotki SAPR $\mathrm{v}$ legkoy promyshlennosti. V sbornike: Nauchnyye issledovaniya i obrazovatel'nyye praktiki v XXI veke: sostoyaniye i perspektivy razvitiya Sbornik nauchnykh trudov po materialam Mezhdunarodnoy nauchno-prakticheskoy konferentsii. OOO «NOVALENSO». 2015. p. 152-153.

21. Murygin V.E., Mezentseva T.V., Chalenko E.A. (2015) Kontseptsiya preobrazovaniya informatsii v sisteme "Konstruktsiya izdeliya Organizatsionnyy protsess yego proizvodstva". $\mathrm{V}$ sbornike: Itogi nauchnykh issledovaniy Sbornik statey Mezhdunarodnoy nauchnoprakticheskoy konferentsii. 2015. p. 17-19.

22. Chalenko E.A., Gruzdeva E.M., Kirsanova E.A., Sanzhiyeva G.V., Shustov YU.S., Aksenova I.A., Vershinina A.V. (2015) Prochnost' okraski materialov k deystviyu pota i stirki v izdeliyakh, podvergayushchikhsya vysokim dinamicheskim nagruzkam. V sbornike: Dizayn, tekhnologii i innovatsii $\mathrm{V}$ tekstil'noy i legkoy promyshlennosti (INNOVATSII - 2015) sbornik materialov mezhdunarodnoy nauchno-tekhnicheskoy konferentsii. Federal'noye gosudarstvennoye byudzhetnoye obrazovatel'noye uchrezhdeniye vysshego professional'nogo obrazovaniya «Moskovskiy gosudarstvennyy universitet dizayna i tekhnologii». 2015. p. 34-36.

23. Aksenova I.A., Chalenko E.A., Safonova N.S., Kirsanova E.A., Vershinina A.V., Sanzhiyeva G.V. (2015) Analiz svoystv nitok, primenyayemykh dlya stachivaniya detaley obolochek plotnogo prileganiya. V sbornike: Dizayn, tekhnologii i innovatsii v tekstil'noy i legkoy promyshlennosti (INNOVATSII - 2015) sbornik materialov mezhdunarodnoy nauchnotekhnicheskoy konferentsii. Federal'noye gosudarstvennoye byudzhetnoye obrazovatel'noye uchrezhdeniye vysshego professional'nogo obrazovaniya «Moskovskiy gosudarstvennyy universitet dizayna i tekhnologii». 2015. p. 4-6.

24. Platova A.A., Chalenko E.A., Kirsanova E.A., Kupriyanova M.S. (2012) Vzaimosvyaz' svoystv materialov i tekhnologicheskogo protsessa izgotovleniya zhenskikh bel'yevykh i korsetnykh izdeliy. Dizayn i tekhnologii. 2012. № 30 (72). p. 98-103. 


\begin{tabular}{l|lr|ll|ll} 
& ISRA (India) & $=\mathbf{1 . 3 4 4}$ & SIS (USA) & $=\mathbf{0 . 9 1 2}$ & ICV (Poland) & $=\mathbf{6 . 6 3 0}$ \\
Impact Factor: & ISI (Dubai, UAE) $=\mathbf{0 . 8 2 9}$ & PUHЦ (Russia) $=\mathbf{0 . 2 0 7}$ & PIF (India) & $=\mathbf{1 . 9 4 0}$ \\
& GIF (Australia) & $\mathbf{0 . 5 6 4}$ & ESJI (KZ) & $=4.102$ & IBI (India) & $=\mathbf{4 . 2 6 0}$ \\
& JIF & $=\mathbf{1 . 5 0 0}$ & SJIF (Morocco) & $=\mathbf{2 . 0 3 1}$ & & \\
\hline
\end{tabular}

25. Trutneva N.E., Chalenko E.A., Zaretskaya G.P. (2013) Dvukhstadiynyy sposob izgotovleniya shveynykh izdeliy. V sbornike: Vzaimodeystviye vysshey shkoly s predpriyatiyami legkoy promyshlennosti: nauka i praktika materialy Mezhdunarodnoy nauchnoprakticheskoy konferentsii, posvyashchennoy 20-letiyu kafedry tekhnologii i materialovedeniya shveynogo proizvodstva.
Kostromskoy gosudarstvennyy tekhnologicheskiy universitet. 2013. p. 22-25.

26. Trutneva N.E., Chalenko E.A., Zaretskaya G.P. (2013) TWO-STAGE METHOD OF GARMENT MANUFACTURING. In the collection: European Science and Technology materials of the VI International research and practice conference. 2013. p. 354-356. 